\title{
PHYSICO-CHEMICAL PROCESSES FOR LANDFILL LEACHATE TREATMENT: EXPERIMENTS AND MATHEMATICAL MODELS
}

\author{
W. Xing, H. H. Ngo* , S. H. Kim, W. S. Guo and P. Hagare \\ University of Technology, Sydney, PO Box 123, Broadway, NSW 2007, Australia
}

\begin{abstract}
In this study, the adsorption of synthetic landfill leachate onto four kinds of activated carbon has been investigated. From the equilibrium and kinetics experiments, it was observed that coal based PAC presented the highest organic pollutants removal efficiency (54\%), followed by coal based GAC (50\%), wood based GAC (33\%) and wood based PAC (14\%). The adsorption equilibrium of PAC and GAC was successfully predicted by Henry-Freundlich adsorption model whilst LDFA+Dual isotherm Kinetics model could describe well the batch adsorption kinetics. The flocculation and flocculation - adsorption experiments were also conducted. The results indicated that flocculation did not perform well on organics removal because of the dominance of low molecular weight organic compounds in synthetic landfill leachate. Consequently, flocculation as pretreatment to adsorption and a combination of flocculation-adsorption could not improve much the organic removal efficiency for the single adsorption process.
\end{abstract}

Keywords: landfill leachate, activated carbon adsorption, adsorption modeling, flocculation

\section{Introduction}

One of the major pollution problems caused by the municipal solid waste (MSW) landfill is leachate, which results from the degradation of the organic fraction of the solid waste in combination with percolating rainwater. Generally, the landfill leachate contains the pollutants that can be divided into three groups: organic matter including dissolved organic matter and xenobiotic organic substances; inorganic matters, such as ammonia, nitrogen, phosphorus, sodium sulphate, iron chlorides; and heavy metals

\footnotetext{
${ }^{*}$ Correspondence: Huu-Hao Ngo, Faculty of Engineering, University of Technology, Sydney, P.O. Box 123, Broadway, NSW 2007, Australia; Tel: +61-2-9514-1693; Fax: +61-2-9514-2633; E-mail: HuuHao.Ngo@uts.edu.au
} 
(e.g. copper, iron, zinc, lead, manganese etc.) [1,2].

The characteristic of landfill leachate is various with different sites and environmental conditions because of the consequence of solid waste composition, age of the waste, operation of the landfill, hydrogeologic conditions in vicinity of the landfill site, rate of the water movement through the waste, landfill temperature, moisture content, $\mathrm{pH}$, landfill chemical/biological activities and seasonal weather variations [2,3]. Generally, the raw landfill leachate presents very high ammonia nitrogen $(2500-5000 \mathrm{mg} / \mathrm{L})$ and COD $(5000-20000 \mathrm{mg} / \mathrm{L})$ which can contaminate ground water and surface water supply and threatens human health when it migrates from the landfill [4].

Technologies developed for landfill leachate treatment can be classified as physical, chemical and biological which are usually applied as an integrated system because it is difficult to achieve the satisfying treatment efficiency by either one of technology alone [5]. As one of the major physical treatment technologies, activated carbon adsorption is widely employed for organic matter, ammonium and toxicity removal in landfill leachate treatment [6 - 9]. Furthermore, flocculation, as an effective chemical technology, has been applied as a useful pretreatment method for removing the nonbiodegradation organic compounds and heavy metals from fresh landfill leachate or as post treatment technology for stabilized leachate [10-13].

The main objectives of this study are (i) to evaluate the typical single physicochemical process in synthetic landfill leachate treatment and their integration in terms of total organic carbon (TOC) removal and (ii) to develop the mathematical models to describe and predict their performance.

\section{Experimental}

\subsection{Materials}

\subsubsection{Synthetic landfill leachate used in the experiments}

The synthetic landfill leachate is representative of secondary treated landfill leachate. The average total organic carbon (TOC) concentration of the synthetic landfill leachate is about $110 \mathrm{mg} / \mathrm{L}$. The composition of synthetic landfill leachate used in the study is shown in Table1. 
Table 1 Compositions of synthetic leachate

\subsubsection{Activated carbon types}

The studies were conducted with four kinds of activated carbons: wood based granular activated carbon (GAC), coal based GAC, wood based powdered activated carbon (PAC) and coal based PAC. The physical properties of these GAC and PAC are shown in Tables 2 .

Table 2 Characteristics of activated carbon used

\subsection{Experiments}

\subsubsection{Adsorption equilibrium and kinetics experiments}

Four kinds of GAC and PAC adsorption capacity with synthetic landfill leachate were evaluated by equilibrium and kinetic adsorption. Equilibrium adsorption was described and predicted with Henry - Freundlich dual isotherm model. Linear driving force approximation (LDFA) model was used to evaluate kinetic adsorption.

Equilibrium adsorption experiments were conducted at room temperature $\left(25^{\circ} \mathrm{C}\right)$. Different doses of GAC or PAC were distributed into $250 \mathrm{~mL}$ flask containing 100ml synthetic landfill leachate. In order to avoid the influence of the light to adsorption, all flasks were covered by aluminum foil. All samples were shaken continuously for 72 hours on a shaking table at speed $130 \mathrm{rpm}$. After 72 hours shaking, samples of synthetic landfill leachate were taken from all flasks and filtered through $0.45 \mu \mathrm{m}$ filter and then analyzed in terms of TOC. In the experiment of kinetics adsorption, GAC or PAC was distributed into 2 liters beaker filled with synthetic landfill leachate at three different concentrations. The solutions with activated carbon were mixed with mechanical stirrer at speed of 110rpm for 6 hours. During the kinetic experiment, samples were taken from these three beakers at different period time and filtered through $0.45 \mu \mathrm{m}$ filter before analyzing TOC.

\subsubsection{Flocculation experiments}

In the flocculation experiments, $\mathrm{FeCl}_{3}$ was used as flocculant to remove contaminants from synthetic landfill leachate. Different doses of $\mathrm{FeCl}_{3}$ were added into six beakers 
of $1 \mathrm{~L}$ volume with synthetic landfill leachate. The experiments were performed in a conventional jar-test apparatus and consisted of three subsequent stages: (i) the initial rapid mixing stage took place for 1 minute at $100 \mathrm{rpm}$; (ii) the following slow mix stage for 30 minutes at $30 \mathrm{rpm}$; and (iii) the final settle stage lasted for another 30 minutes. After the settling period, the supernatant was withdrawn from beaker and used for TOC and chemical oxygen demand (COD) analyses to decide the optimum dose of $\mathrm{FeCl}_{3}$.

\subsubsection{Flocculation as pretreatment to adsorption}

The experimental process was consisted of two stage: the first one is flocculation, the optimum dose of $\mathrm{FeCl}_{3}$ were added into three 2-L beakers with synthetic landfill leachate and the flocculation process is the same as that described in section2.2.2. The supernatant after the settlement was used as influent in the following adsorption stage. In the adsorption stage, the GAC or PAC was distributed into 2-L beakers with $1.5 \mathrm{~L}$ supernatant of flocculation at different concentrations, and the kinetics experiments were conducted as the demonstration in section 2.2.1. The treatability of this process was described by the removal efficiency of TOC.

\subsubsection{Flocculation-adsorption}

In the internal integration of flocculation into adsorption experiments, the optimum dose of $\mathrm{FeCl}_{3}$ and three different doses of activated carbon (PAC and GAC) were added into three $2 \mathrm{~L}$ beakers with synthetic landfill leachate together and then the conventional jar-test was conducted. After the settling period, the supernatants were withdrawn from three beakers and analyzed TOC.

\subsection{Analysis}

TOC concentration of water sample was measured using Analytikjena Multi N/C 2000 analyzer.

\section{Results and discussion}

\subsection{Performance of adsorption}

a. Wood based GAC

Figures 1(a) and 1(b) show the results of wood based GAC equilibrium and kinetics adsorption. As can be seen from the figures, the removal efficiency of TOC is the 
function of GAC dosage. The wood based GAC could remove approximately $33 \%$ TOC at dose of $30 \mathrm{~g} / \mathrm{L}$ while only $15 \%$ TOC removal efficiency could be obtained at dose of $10 \mathrm{~g} / \mathrm{L}$. For the results of kinetics experiment, TOC removal efficiency increased dramatically in the first $45 \mathrm{mins}$ and then it remained stable. In the other word, during the first 45 minutes, the available sites on the GAC surface for adsorption were abundant which resulted in the organic adsorption. When all the adsorption sites were occupied and the rate of adsorption and desorption were balanced, organic removal by GAC adsorption were constant.

Figure 1(a) Equilibrium adsorption of wood based GAC (Average initial TOC $=110 \mathrm{mg} / 1$, mixing rate $=130 \mathrm{rpm}$, contact time $=72 \mathrm{hrs}$ )

Figure 1(b) Kinetics adsorption of wood based GAC (Average initial TOC=110mg/l, mixing rate $=110 \mathrm{rpm}$, contact time $=6 \mathrm{hrs}$ )

\section{b. Coal based GAC}

The results of coal based GAC adsorption equilibrium and kinetic are presented in Figures 2(a) and 2(b). As expected, higher coal based GAC dosage resulted in better organic adsorption due to larger GAC surface. For all the three different dosage investigated, organic matter in the synthetic landfill leachate was quickly adsorbed within the first $45 \mathrm{mins}$, after that the adsorption and desorption achieved balance, the organic adsorption rate by coal based GAC remained almost constant.

Figure 2(a) Equilibrium adsorption of coal based GAC (Average initial $\mathrm{TOC}=110 \mathrm{mg} / \mathrm{l}$, mixing rate $=130 \mathrm{rpm}$, contact time $=72 \mathrm{hrs}$ )

Figure 2(b) Kinetics adsorption of coal based GAC (Average initial TOC=110mg/l, mixing rate $=110 \mathrm{rpm}$, contact time $=6 \mathrm{hrs}$ )

\section{c. Wood based PAC}

The removal of organic matter in terms of TOC by wood based PAC is shown in Figures 3(a) and 3 (b). The results indicated that the wood based PAC adsorption resulted in very low organic matter removal from synthetic landfill leachate (lower than $15 \%$ with all the concentration of wood based PAC). The poor performance of this kind of PAC suggested that this wood based PAC was not suitable to use in removing organic matter from synthetic landfill leachate which consists a very 
complex component.

Figure 3(a) Equilibrium adsorption of wood based PAC (Average initial $\mathrm{TOC}=110 \mathrm{mg} / \mathrm{l}$, mixing rate $=130 \mathrm{rpm}$, contact time $=72 \mathrm{hrs}$ )

Figure 3(b) Kinetics adsorption of wood based PAC (Average initial TOC=110mg/l, mixing rate $=110 \mathrm{rpm}$, contact time $=6 \mathrm{hrs}$ )

\section{d. Coal based PAC}

As can be see in Figures 4(a) and 4 (b), TOC removal by coal based PAC adsorption increased with the increase of PAC dosage as expected. A 30g/L dose of coal based PAC led to a very high amount of organic matter adsorption (approximately 54\% TOC removal). Kinetics adsorption experimental results show that the removal of organic matter as the function of adsorption time. In the first 45 minutes, the coal based PAC adsorbed organic contaminants rapidly and then the organic removal stayed constant until 6hours.

Figure 4(a) Equilibrium adsorption of coal based PAC (Average initial TOC=110mg/l, mixing rate $=130 \mathrm{rpm}$, contact time $=72 \mathrm{hrs}$ )

Figure 4(b) Kinetics adsorption of coal based PAC (Average initial TOC=110mg/l, mixing rate $=110 \mathrm{rpm}$, contact time $=6 \mathrm{hrs}$ )

Compared with the adsorption capability of PAC and GAC discussed above, it is observed that the coal based PAC is the adsorbent that achieved the best organic removal (54\% TOC removal at dose of 30g/l), followed by coal based GAC and wool based GAC which only removed $50 \%$ and $33 \%$ organic matter at a dose of $30 \mathrm{~g} / \mathrm{L}$, respectively (Figure 5). The wood based PAC is the one present the lowest removal capability for organic matter (less than $15 \%$ TOC removal) from synthetic landfill leachate. The results indicated that the organic removal efficiency is correspondent to the surface area of activated carbon. The coal based PAC has the largest surface area to adsorbed organic contaminants from synthetic landfill leachate, thus, it performed better TOC removal efficiency than other activated carbons.

\subsection{Performance of flocculation as pretreatment to adsorption}

Figures 6(a) (b) and (c) show the removal efficiency of organic matter from synthetic landfill leachate by using ferric chloride flocculation as pretreatment for activated 
carbon adsorption. Although flocculation was used as pretreatment, compared with single activated carbon adsorption, the combined process did not perform much better removal efficiency of organic matter (average increasing of $4 \%$ for these three experiments). It can be explained as flocculation can effectively remove high molecular weight organic matters while most of organic compounds containing in the synthetic landfill leachate used are low in molecular weight (Acetic acid, 60.05g/mol; Propionic acid, $74.08 \mathrm{~g} / \mathrm{mol}$; Butyric, $88.11 \mathrm{~g} / \mathrm{mol}$ ), thus flocculation pretreatment is not very helpful in removing low molecular weight organic contaminants from synthetic landfill leachate.

Figure 6(a) Flocculation as pretreatment to wood based GAC for TOC removal from landfill leachate (average initial $\mathrm{TOC}=110 \mathrm{mg} / \mathrm{l}$, mixing rate $=110 \mathrm{rpm}$, contact time $=$ $6 \mathrm{hrs})$

Figure 6(b) Flocculation as pretreatment to coal based GAC for TOC removal from landfill leachate (average initial $\mathrm{TOC}=110 \mathrm{mg} / \mathrm{l}$, mixing rate $=110 \mathrm{rpm}$, contact time $=$ $6 \mathrm{hrs})$

Figure 6(c) Flocculation as pretreatment to coal based PAC for TOC removal from landfill leachate (average initial $\mathrm{TOC}=110 \mathrm{mg} / \mathrm{l}$, mixing rate $=110 \mathrm{rpm}$, contact time $=$ $6 \mathrm{hrs})$

\subsection{Performance of internal integration of flocculation into adsorption}

The preliminary testing on flocculation-adsorption experiments are presented in Figure 7. The results demonstrated that the TOC removal efficiency was quite low even lower than that by the adsorption process only. One of the main possible reasons for the poor performance of combined flocculation-adsorption is that compared with the adsorption normal mixing intensity (between $110 \mathrm{rpm}$ and $130 \mathrm{rpm}$ ), the intensity of $30 \mathrm{rpm}$ during the flocculation-adsorption process was not sufficient for activated carbon adsorption. In addition, the trial conditions ( $\mathrm{PAC}$ and $\mathrm{FeCl}_{3}$ ) are not the optimum conditions. Further study is necessary to find out the possible and proper way to make this process work well for landfill leachate treatment. The performance comparison of different processes is shown in Table 3.

Figure 7 Combination of flocculation-adsorption for TOC removal from landfill 
leachate (rapid mixing gradient rate $=100 \mathrm{rpm}$, slow mixing gradient rate $=30 \mathrm{rpm}$, average initial $\mathrm{TOC}=110 \mathrm{mg} / \mathrm{L}$ )

Table 3 Performance comparison of adsorption and integration of flocculation and adsorption

\subsection{Mathematical models}

\subsubsection{Equilibrium modeling}

In this study, the Henry - Freundlich dual isotherm model was employed to describe and predict the GAC and PAC equilibrium adsorption. The Henry - Freundlich isotherm is the model combined Henry's law and Freundlich model. It is expressed by Equation 1:

$q=K \cdot C_{e}+k_{F} \cdot C_{e}^{1 / n}$

where $q$ is the adsorbed amount $(\mathrm{mg} / \mathrm{g}), C_{e}$ is the equilibrium organic concentration (mg/L), K , $\mathrm{K}_{\mathrm{F}}, \mathrm{n}$ are Henry-Freundlich constants.

The equilibrium parameters obtained from simulation are presented in Table 4.

Table 4 Henry-Freundlich dual isotherm constants $\left(25^{\circ} \mathrm{C}\right)$

As can be seen in Figure 8, the model results indicated that Henry's law fitted well the data in the region of Ce less than $80 \mathrm{mg} / \mathrm{L}$ while the rest of region was successfully predicted by Freundlich model. Therefore, the combined model was able to apply for describing and simulating the results.

Figure 8 Adsorption equilibrium of synthetic landfill leachate by four kinds of activated carbon with Henry - Freundlich dual model $\left(25^{\circ} \mathrm{C}\right)$

\subsubsection{Kinetics modeling}

The adsorption rate of adsorbate by activated carbon is linearly proportional to a driving force using the LDFA model, defined as the difference between the surface concentration and the average adsorbed-phase concentration. This model is very simple and easy to apply for adsorption kinetics experimental modelling [14]. 


$$
\frac{d q}{d t}=\frac{3 \times k_{f}}{R \times \rho_{p}}\left(c_{i}-c_{s}\right)
$$

Where $R$ is radius of adsorbent $(\mathrm{m}), k_{f}$ is overall mass transfer coefficient $(\mathrm{m} / \mathrm{s}), \rho_{p}$ is

density of particle $\left(\mathrm{kg} / \mathrm{m}^{3}\right), c_{i}$ is initial concentration of adsorbate in fluid phase $(\mathrm{mg} / \mathrm{l})$, $c_{s}$ is concentration of adsorbate in fluid phase at equilibrium $(\mathrm{mg} / \mathrm{l})$.

Table 5 presents the kinetics constants of LDFA+Dual isotherm kinetics models for activated carbon adsorption. These values could be applied to predict the kinetic experimental data. Regardless of the amount of the adsorbents, kinetic constants had the same value with same concentration and temperature [15]. The kinetics adsorption experimental data of four kinds of activated carbon with synthetic landfill leachate were well fitted well to the LDFA +dual model (Figure 9 - 12).

Table 5 LDFA+ Dual isotherm kinetics constants

Figure 9 LDFA+Dual isotherm kinetics for TOC adsorption on coal-based GAC Figure 10 LDFA+Dual isotherm kinetics for TOC adsorption on wood-based GAC Figure 11 LDFA+Dual isotherm kinetics for TOC adsorption on coal-based PAC Figure 12 LDFA+ Dual isotherm kinetics for TOC adsorption on wood-based PAC

\section{Conclusions}

- Coal based PAC exhibited a highest organic matter removal rate (54\%), followed by coal based GAC (50\%) and wool based GAC (33\%). The wood based PAC showed the lowest adsorption capacity on TOC removal from synthetic landfill leachate due to its smaller surface area.

- Flocculation pretreatment was not effective in removing low molecular weight organic contaminants from synthetic landfill leachate. The combination of flocculation-adsorption did not perform well on organic matter removal from synthetic landfill leachate.

- The GAC and PAC adsorption equilibrium with the synthetic landfill leachate fitted well with Henry - Freundlich adsorption model. The batch adsorption kinetics with organic matter was successfully predicted by LDFA \& Dual Isotherm Kinetics model.

\section{Acknowledgements}


This study was partial funded by the Institute of Water and Environment Resource Management (IWERM), University of Technology, Sydney (UTS). The authors are also grateful to Activated Carbon Technologies Pty Ltd, Australia for their support in providing the activated carbons.

\section{References}

[1] McArdle, J.L., Arozarena, M.M., Gallagher, W.E. (1988). Treatment of hazardous waste leachate: unit operation and cost, New Jersey, Noyes Data Corporation.

[2] Westlake, K. (1995). Landfill waste pollution and control, England, Albion publishing limited.

[3] Iaconi, C.D., Ramadori, R., Lopez, A. (2006). Combined biological and chemical degradation for treating a mature municipal landfill leachate, Biochemical Engineering Journal, 31, 118-124.

[4] Chan, G.Y.S., Chang, J., Kurniawan, T.A., Fu, C.X., Jiang, H., Je, Y. (2007). Removal of non-biodegradable compounds from stabilized leachate using VSEPRO membrane filtration, Desalination, 202, 310-317.

[5] Uygur, A., Kargi, F.(2004). Biological nutrient removal from pre-treated landfill leachate in a sequencing batch reactor, Journal of environmental management, 71 , 9-14.

[6] Rivas, F.J., Beltran, F. Carvalho, F., Acedo, B., Gimeno, O. (2004). Stabilized leachates: sequential coagulation-flocculation + chemical oxidation process, Journal of hazardous materials, B116, 95-102.

[7] Rodriguez, J., Castrillon, L., Maranon, E., Sastre, H., Fernandez, E. (2004). Removal of non-biodegradable organic matter from landfill leachates by adsorption, Water research, 38, 3297-3303.

[8] Aziz, H.A., Adlan, M.N., Zahari, M.S.M., Alias, S. (2004). Removal of ammonianitrogen $\left(\mathrm{NH}_{3}-\mathrm{N}\right)$ from municipal solid waste leachate by using activated carbon and lime stone, Waste manage, 22, 371-375.

[9] Kurniawan, T.A., Lo, W.H., Chan, G.Y.S. (2006). Degradation of recalcitrant compounds from stabilized landfill leachate using a combination of ozone-GAC adsorption treatment, Journal of hazardous materials, B137, 443-455.

[10]Amokrane, A., Comel, C., Veron, J. (1997). Landfill leachates pretreatment by coagulation-flocculation, Water research, 31, 2775-2782.

[11] Tatsi, A. A., Zouboulis, A.I., Matis, K.A., Samaras, P. (2003).Coagulationflocculation pretreatment of sanitary landfill leachate, Chemosphere, 53, 737-744.

[12] Galvez, A., Zamorano, M., Ramos, A., Hontoria, E. (2005). Coagulationflocculation pretreatment of a partially stabilized leachate from a sanitary landfill site at Alhendin (Granada, Southern Spain), Journal of environmental science and health, 40, 1741-1751.

[13]Ntampou, X., Zouboulis, A.I., Samaras, P. (2005). Appropriate combination of physico-chmical methods (coagulation/ flocculation and ozonation) for the efficient treatment of landfill leachates, Chemosphere, 62,722-730.

[14]Lee, S.H., Vigneswaran, S., Moon, H. (1997). Adsorption of phosphorus in saturated slag media columns, Sparation and Purification Technology, 12,109118.

[15] Lee, J.W., Yang, T.H., Shim, W.G., Kwon, T.O., Moon, I.S. (2007). Equilibria and dynamics of liquid-phase trinitrotoluene adsorption on granular activated carbon: Effect of temperature and $\mathrm{pH}$, Journal of hazardous materials, 141(1) 185-192. 
Table 1 Compositions of synthetic leachate

\begin{tabular}{|c|c|}
\hline Component & Per liter \\
\hline Acetic acid & $0.14 \mathrm{ml}$ \\
\hline Propionic acid & $0.1 \mathrm{ml}$ \\
\hline Butyric acid & $0.02 \mathrm{ml}$ \\
\hline $\mathrm{K}_{2} \mathrm{HPO}_{4}$ & $0.6 \mathrm{mg}$ \\
\hline $\mathrm{KHCO}_{3}$ & $6.24 \mathrm{mg}$ \\
\hline $\mathrm{K}_{2} \mathrm{CO}_{3}$ & $6.48 \mathrm{mg}$ \\
\hline $\mathrm{NaCl}$ & $28.8 \mathrm{mg}$ \\
\hline $\mathrm{NaNO}_{3}$ & $1 \mathrm{mg}$ \\
\hline $\mathrm{NaHCO}_{3}$ & $60.24 \mathrm{mg}$ \\
\hline $\mathrm{CaCl}_{2}$ & $57.64 \mathrm{mg}$ \\
\hline $\mathrm{MgCl}_{2} \cdot 6 \mathrm{H}_{2} \mathrm{O}$ & $62.28 \mathrm{mg}$ \\
\hline $\mathrm{MgSO}_{4}$ & $3.12 \mathrm{mg}$ \\
\hline $\mathrm{NH}_{4} \mathrm{HNO}_{3}$ & $48.78 \mathrm{mg}$ \\
\hline $\mathrm{CO}\left(\mathrm{NH}_{2}\right)_{2}$ & $13.18 \mathrm{mg}$ \\
\hline $\mathrm{Na}_{2} \mathrm{~S} \bullet 9 \mathrm{H}_{2} \mathrm{O}$ & Titrate to Eh-120mv:-180mv \\
\hline $\mathrm{NaOH}$ & Trite to $\mathrm{pH}=5.8-6.0$ \\
\hline Trace metal solution(TMS) & $0.02 \mathrm{ml}$ \\
\hline Tap Water & to make $1 \mathrm{~L}$ \\
\hline \multicolumn{2}{|c|}{ Composition of trace metal solution (TMS) } \\
\hline $\mathrm{FeSO}_{4}$ & $2000 \mathrm{mg}$ \\
\hline $\mathrm{H}_{3} \mathrm{BO} 4$ & $50 \mathrm{mg}$ \\
\hline $\mathrm{ZnSO}_{4} \cdot 7 \mathrm{H}_{2} \mathrm{O}$ & $50 \mathrm{mg}$ \\
\hline $\mathrm{CuSO}_{4} \cdot 5 \mathrm{H}_{2} \mathrm{O}$ & $40 \mathrm{mg}$ \\
\hline $\mathrm{MnSO}_{4} \cdot 7 \mathrm{H}_{2} \mathrm{O}$ & $500 \mathrm{mg}$ \\
\hline$\left(\mathrm{NH}_{4}\right)_{6} \mathrm{Mo}_{7} \mathrm{O}_{24} \bullet 4 \mathrm{H}_{2} \mathrm{O}$ & $50 \mathrm{mg}$ \\
\hline $\mathrm{Al}_{2}\left(\mathrm{SO}_{4}\right)_{3} \bullet 16 \mathrm{H}_{2} \mathrm{O}$ & $30 \mathrm{mg}$ \\
\hline $\mathrm{CoSO}_{4} \cdot 7 \mathrm{H}_{2} \mathrm{O}$ & $150 \mathrm{mg}$ \\
\hline $\mathrm{NiSO}_{4} \cdot 6 \mathrm{H}_{2} \mathrm{O}$ & $500 \mathrm{mg}$ \\
\hline $96 \% \mathrm{H}_{2} \mathrm{SO}_{4}$ & $1 \mathrm{ml}$ \\
\hline Distilled water & to make $1 \mathrm{~L}$ \\
\hline
\end{tabular}


Table 2 Characteristics of activated carbon types used

\begin{tabular}{lllll}
\hline \multirow{2}{*}{ Specifications } & \multicolumn{4}{c}{ Estimated Value } \\
\cline { 2 - 5 } & $\begin{array}{l}\text { wood based } \\
\text { GAC }\end{array}$ & $\begin{array}{l}\text { coal based } \\
\text { GAC }\end{array}$ & $\begin{array}{l}\text { wood based } \\
\text { PAC }\end{array}$ & $\begin{array}{l}\text { coal based } \\
\text { PAC }\end{array}$ \\
\hline $\begin{array}{l}\text { Iodine Number, } \\
\text { mg/(g.min) }\end{array}$ & 800 & $>1100$ & 900 & $>1300$ \\
$\begin{array}{l}\text { Maximum Ash content } \\
\text { Maximum Moisture } \\
\text { content }\end{array}$ & $5 \%$ & $10 \%$ & $6 \%$ & $12 \%$ \\
$\begin{array}{l}\text { Surface Area (BET } \\
\left.\mathrm{m}^{2} / \mathrm{g}\right)\end{array}$ & $5 \%$ & $3 \%$ & $5 \%$ & $8 \%$ \\
Type & $>1100$ & $>1100$ & 882 & $>1300$ \\
\hline
\end{tabular}


Table 3 Performance comparison of adsorption and integration of flocculation and adsorption

\begin{tabular}{|c|c|c|c|c|}
\hline \multirow{2}{*}{ Type } & \multirow{2}{*}{$\begin{array}{c}\text { Dose } \\
(\mathrm{g} / \mathrm{L})\end{array}$} & \multicolumn{3}{|c|}{ TOC Removal Efficiency (\%) } \\
\cline { 3 - 5 } & & Adsorption & $\begin{array}{c}\text { Flocculation as } \\
\text { pretreatment to } \\
\text { adsorption }\end{array}$ & $\begin{array}{c}\text { Internal integration } \\
\text { of flocculation into } \\
\text { adsorption process }\end{array}$ \\
\hline \multirow{2}{*}{$\begin{array}{c}\text { Wood based } \\
\text { GAC }\end{array}$} & 15 & 15 & 21 & 14 \\
\cline { 2 - 5 } & 20 & 25 & 28 & 22 \\
\cline { 2 - 5 } & 30 & 33 & 36 & 19 \\
\hline \multirow{3}{*}{ Coal based GAC } & 15 & 24 & 29 & 34 \\
\cline { 2 - 5 } & 20 & 37 & 40 & 32 \\
\hline \multirow{3}{*}{ Coal based PAC } & 30 & 44 & 47 & 35 \\
\cline { 2 - 5 } & 20 & 36 & 41 & 44 \\
\cline { 2 - 5 }
\end{tabular}


Table 4 Henry-Freundlich dual isotherm constants $\left(25^{\circ} \mathrm{C}\right)$

\begin{tabular}{c|c|c|c|c}
\hline & Coal-based PAC & Coal-based GAC & Wood-based GAC & Wood-based PAC \\
\hline \hline $\mathrm{K}$ & 0.0390 & 0.0339 & 0.0136 & 0.0047 \\
\hline $\mathrm{k}_{\mathrm{F}}$ & $2.41 \mathrm{E}-22$ & $2.42 \mathrm{E}-21$ & $3.97 \mathrm{E}-21$ & $8.1 \mathrm{E}-131$ \\
\hline $\mathrm{n}$ & 0.0911 & 0.0946 & 0.0957 & 0.0154 \\
\hline
\end{tabular}


Table 5 LDFA+ Dual isotherm kinetics constants

\begin{tabular}{c|c|c|c|c}
\hline & Coal-based PAC & Coal-based GAC & Wood-based GAC & Wood-based PAC \\
\hline \hline $\mathrm{k}_{\mathrm{f}}$ & $8.0 \mathrm{E}-08$ & $1.0 \mathrm{E}-06$ & $1.1 \mathrm{E}-06$ & $3.6 \mathrm{E}-06$ \\
\hline $\mathrm{R}^{2}$ & 0.975 & 0.980 & 0.984 & 0.986 \\
\hline
\end{tabular}


Figure 1(a) Equilibrium adsorption of wood based GAC (Average initial $\mathrm{TOC}=110 \mathrm{mg} / \mathrm{l}$, mixing rate $=130 \mathrm{rpm}$, contact time $=72 \mathrm{hrs}$ )

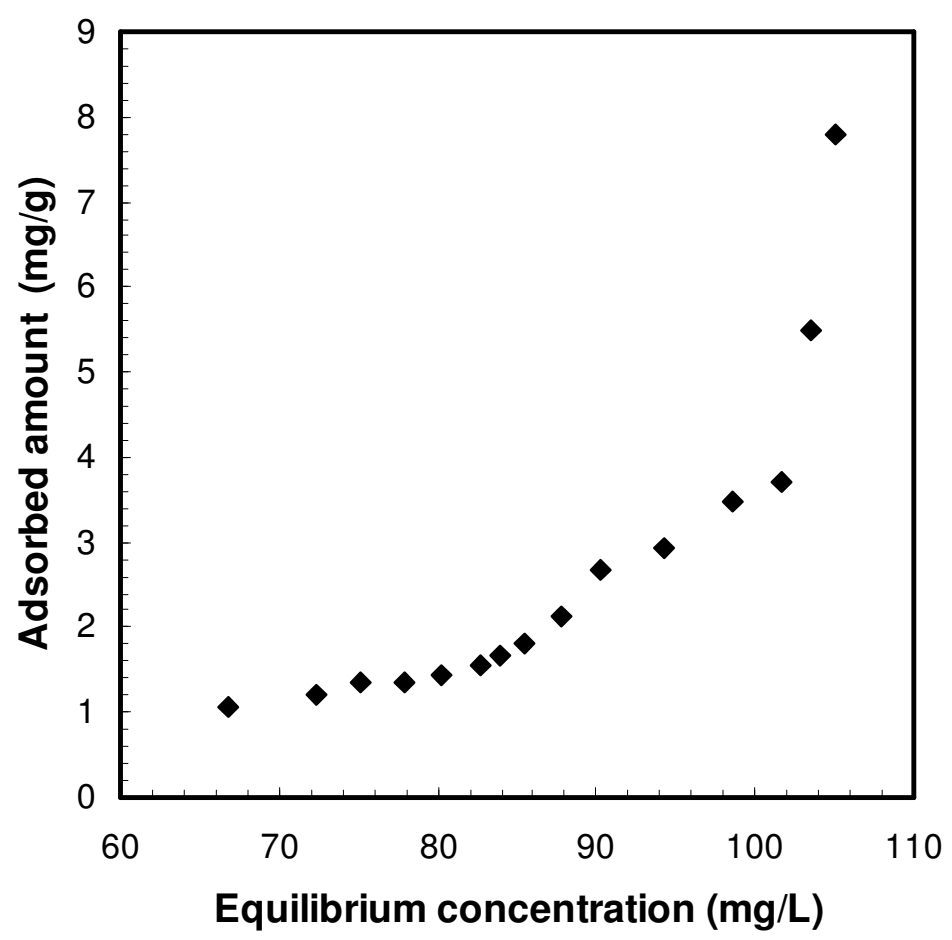


Figure 1(b) Kinetics adsorption of wood based GAC (Average initial TOC=110mg/l, mixing rate $=110 \mathrm{rpm}$, contact time $=6 \mathrm{hrs}$ )

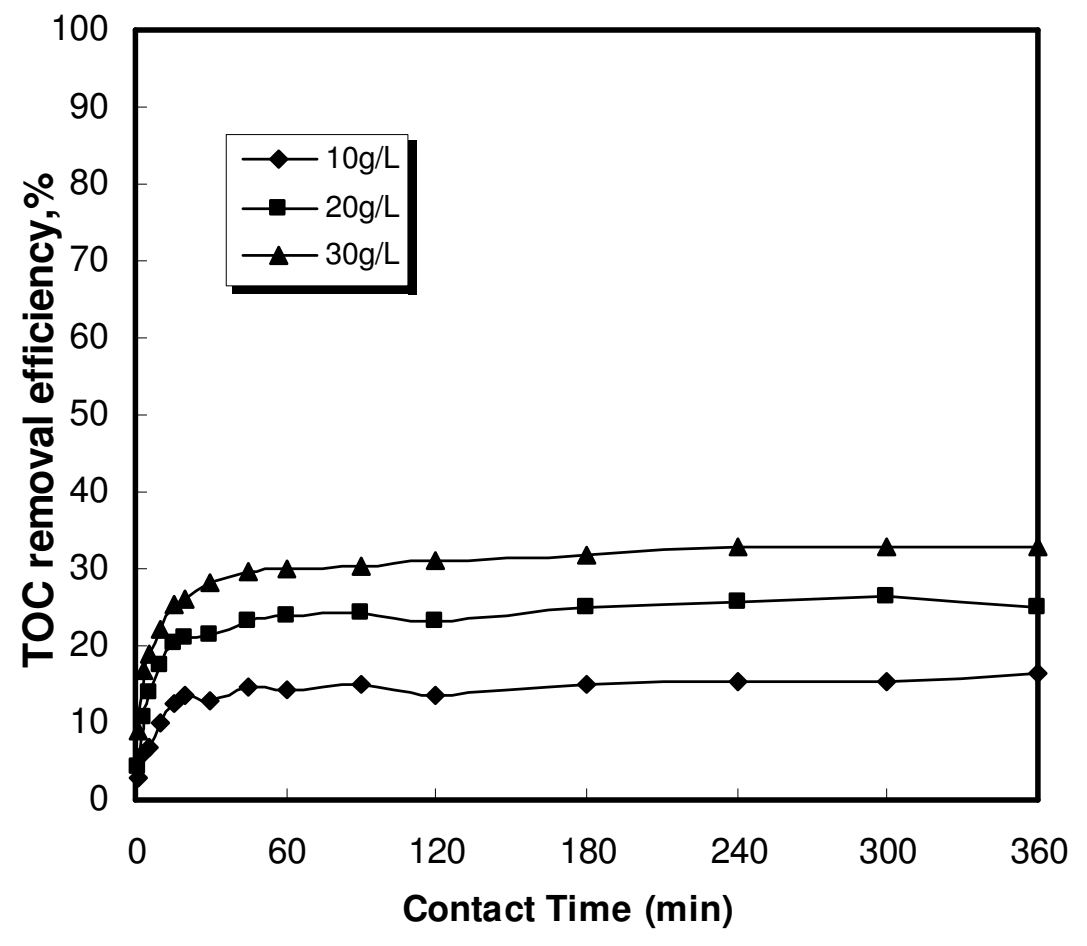


Figure 2(a) Equilibrium adsorption of coal based GAC (Average initial $\mathrm{TOC}=110 \mathrm{mg} / \mathrm{l}$, mixing rate $=130 \mathrm{rpm}$, contact time $=72 \mathrm{hrs}$ )

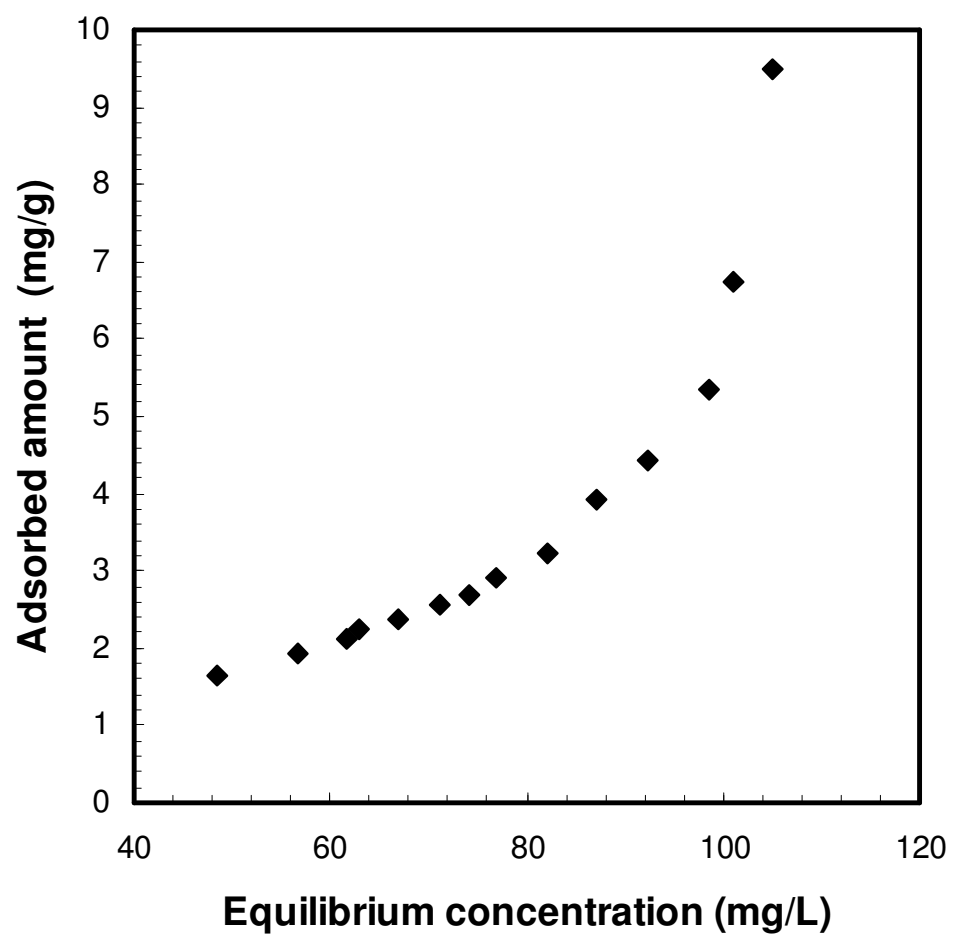


Figure 2(b) Kinetics adsorption of coal based GAC (Average initial TOC $=110 \mathrm{mg} / \mathrm{l}$, mixing rate $=110 \mathrm{rpm}$, contact time $=6 \mathrm{hrs}$ )

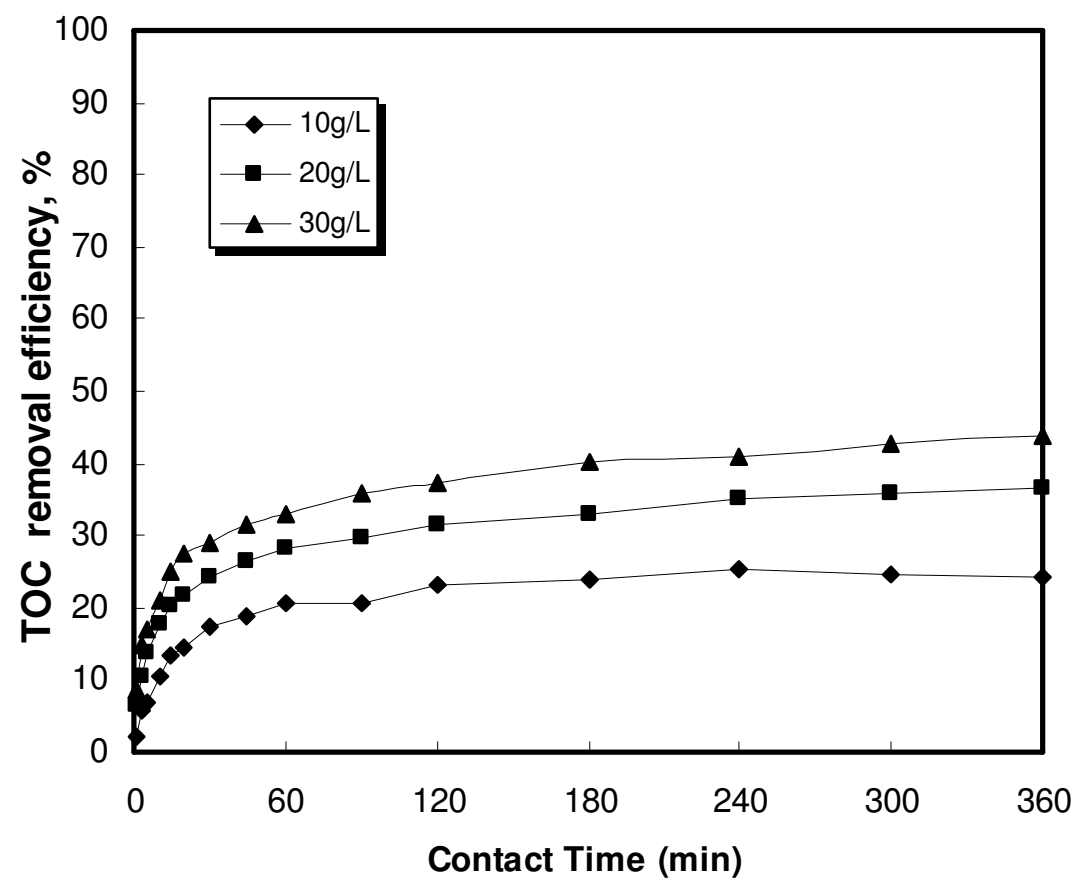


Figure 3(a) Equilibrium adsorption of wood based PAC (Average initial $\mathrm{TOC}=110 \mathrm{mg} / \mathrm{l}$, mixing rate $=130 \mathrm{rpm}$, contact time $=72 \mathrm{hrs}$ )

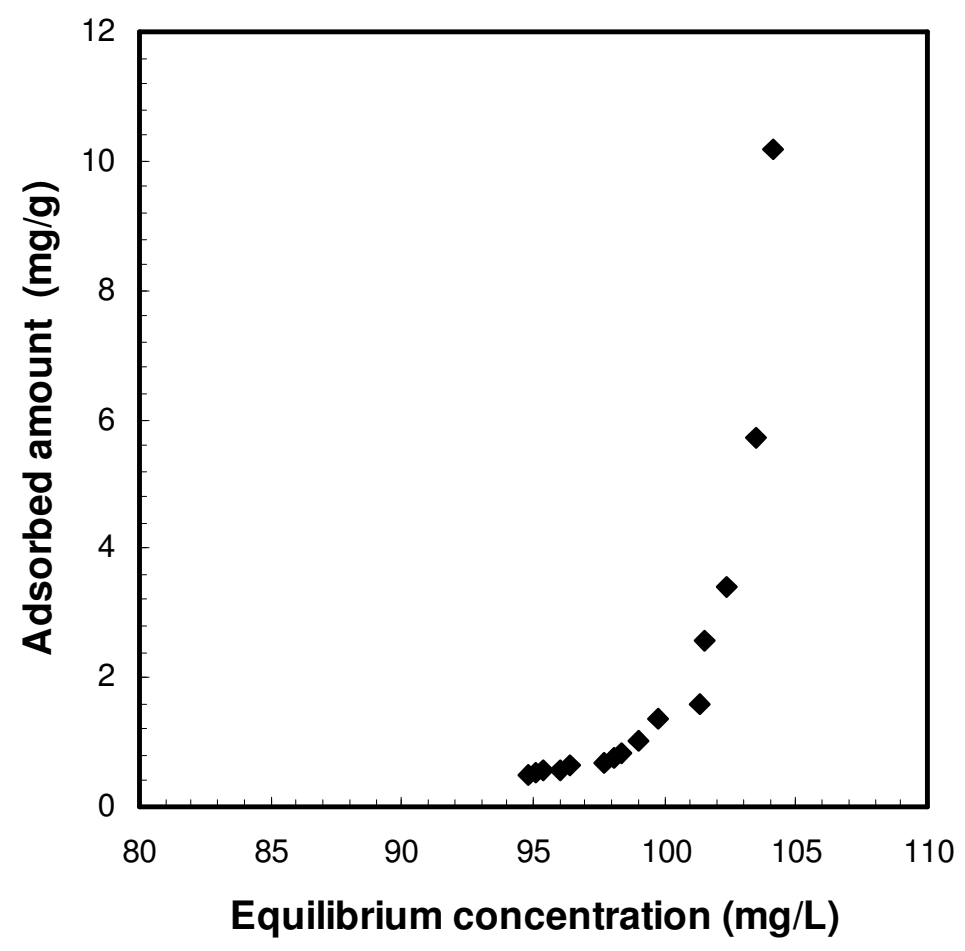


Figure 3(b) Kinetics adsorption of wood based PAC (Average initial TOC $=110 \mathrm{mg} / \mathrm{l}$, mixing rate $=110 \mathrm{rpm}$, contact time $=6 \mathrm{hrs}$ )

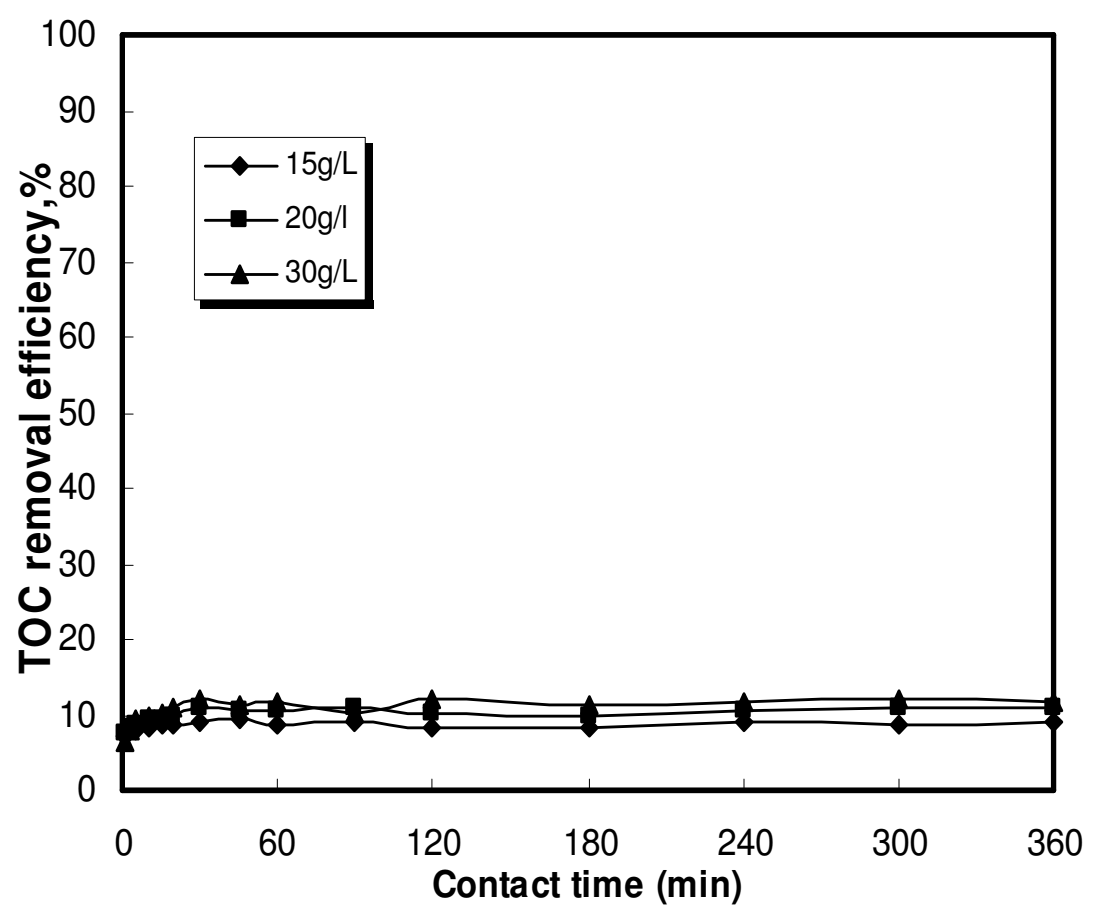


Figure 4(a) Equilibrium adsorption of coal based PAC (Average initial TOC $=110 \mathrm{mg} / \mathrm{l}$, mixing rate $=130 \mathrm{rpm}$, contact time $=72 \mathrm{hrs}$ )

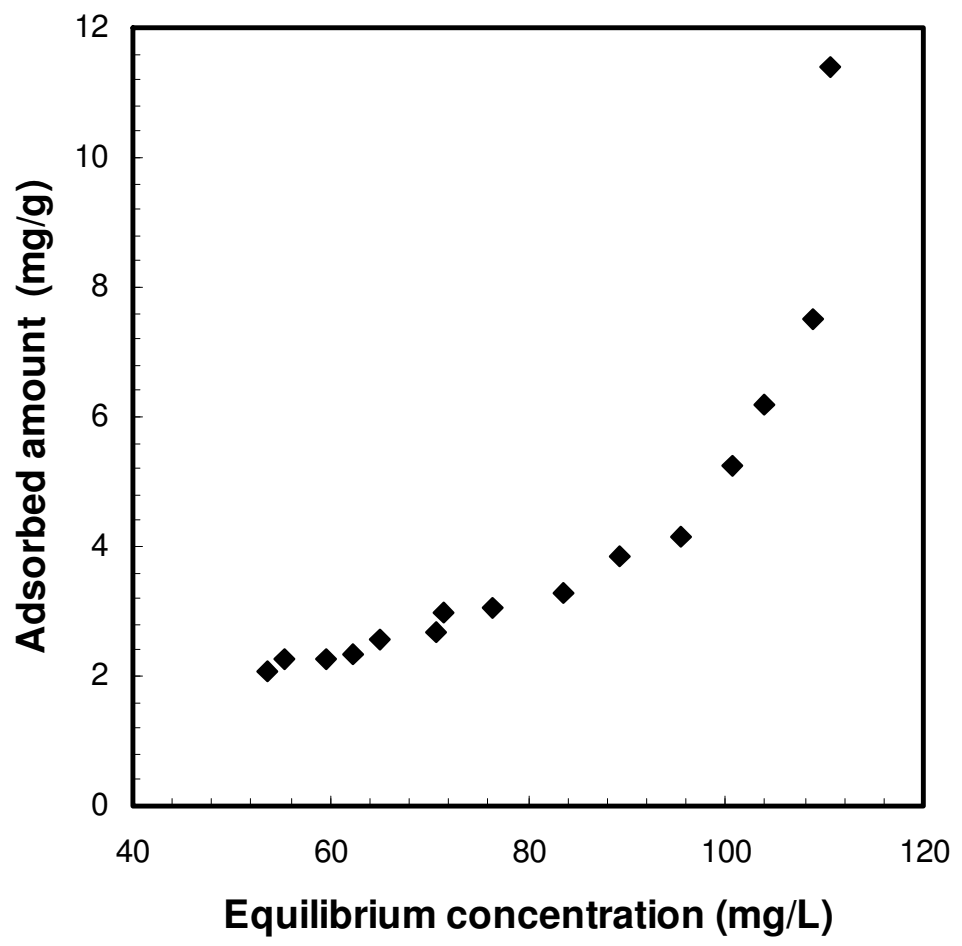


Figure 4(b) Kinetics adsorption of coal based PAC (Average initial TOC $=110 \mathrm{mg} / \mathrm{l}$, mixing rate $=110 \mathrm{rpm}$, contact time $=6 \mathrm{hrs}$ )

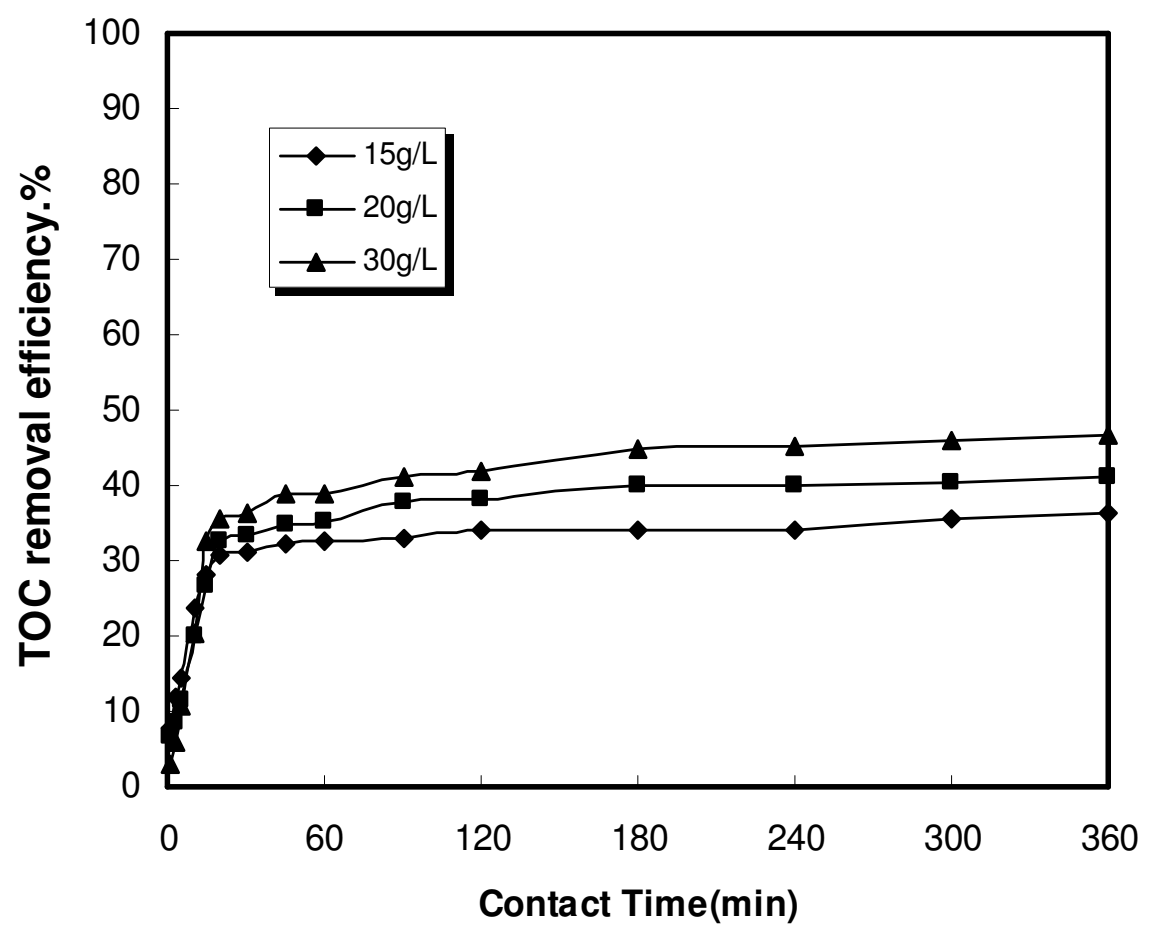


Figure 5 Comparison of TOC removal efficiency by four kinds of activated carbon

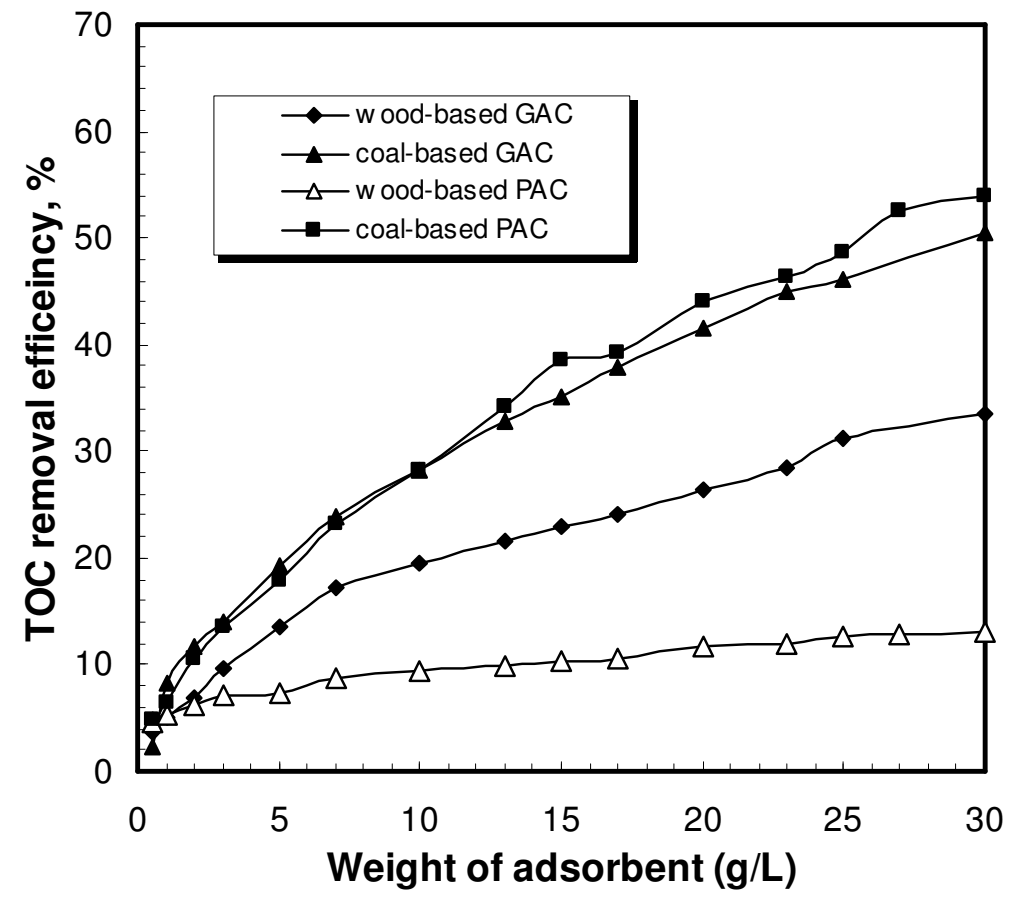


Figure 6(a) Flocculation as pretreatment to wood based GAC for TOC removal from landfill leachate (average initial $\mathrm{TOC}=110 \mathrm{mg} / \mathrm{l}$, mixing rate $=110 \mathrm{rpm}$, contact time $=$ $6 \mathrm{hrs})$

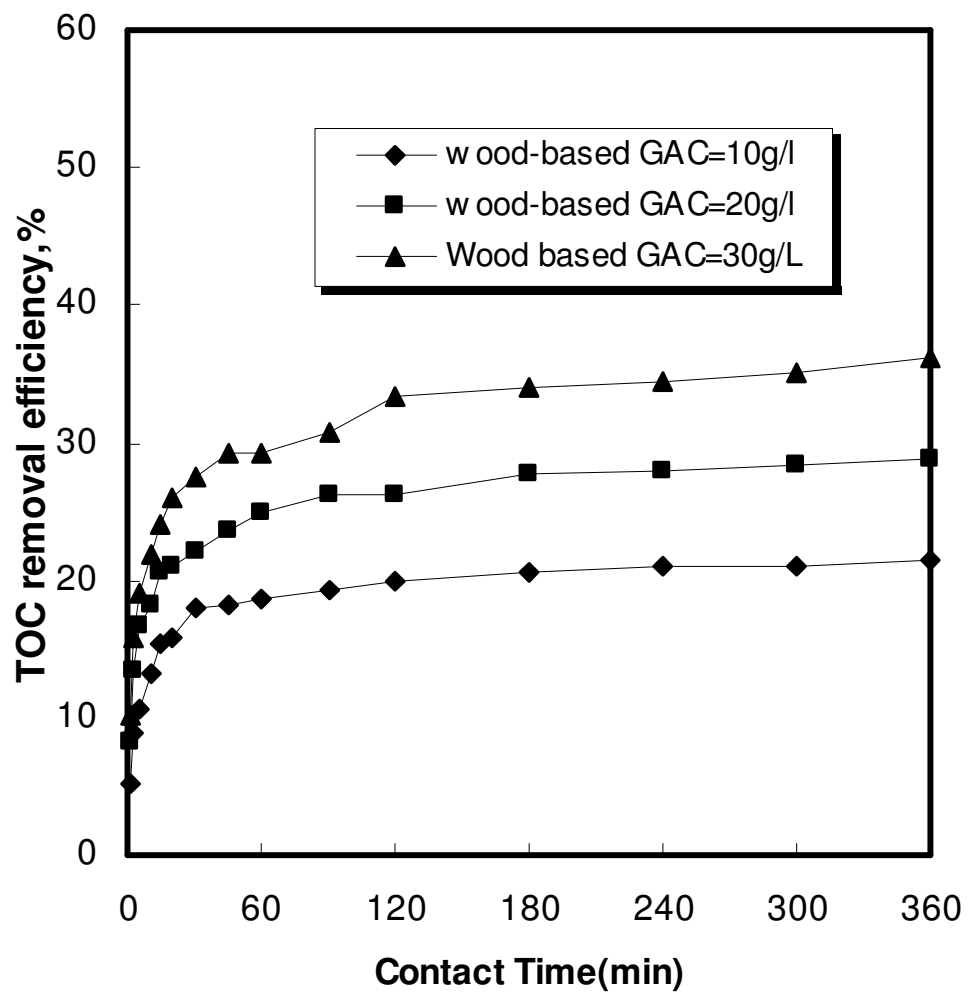


Figure 6(b) Flocculation as pretreatment to coal based GAC for TOC removal from landfill leachate (average initial $\mathrm{TOC}=110 \mathrm{mg} / \mathrm{l}$, mixing rate $=110 \mathrm{rpm}$, contact time $=$ $6 \mathrm{hrs})$

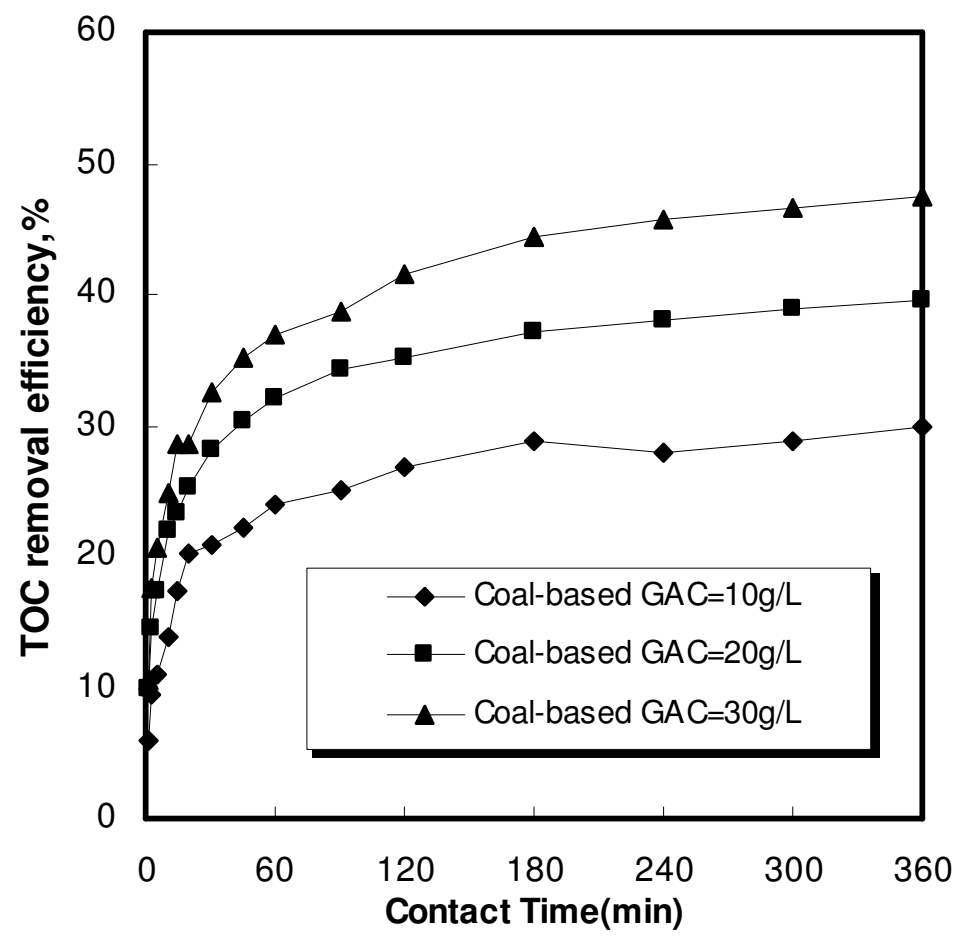


Figure 6(c) Flocculation as pretreatment to coal based PAC for TOC removal from landfill leachate (average initial $\mathrm{TOC}=110 \mathrm{mg} / \mathrm{l}$, mixing rate $=110 \mathrm{rpm}$, contact time $=$ $6 \mathrm{hrs})$

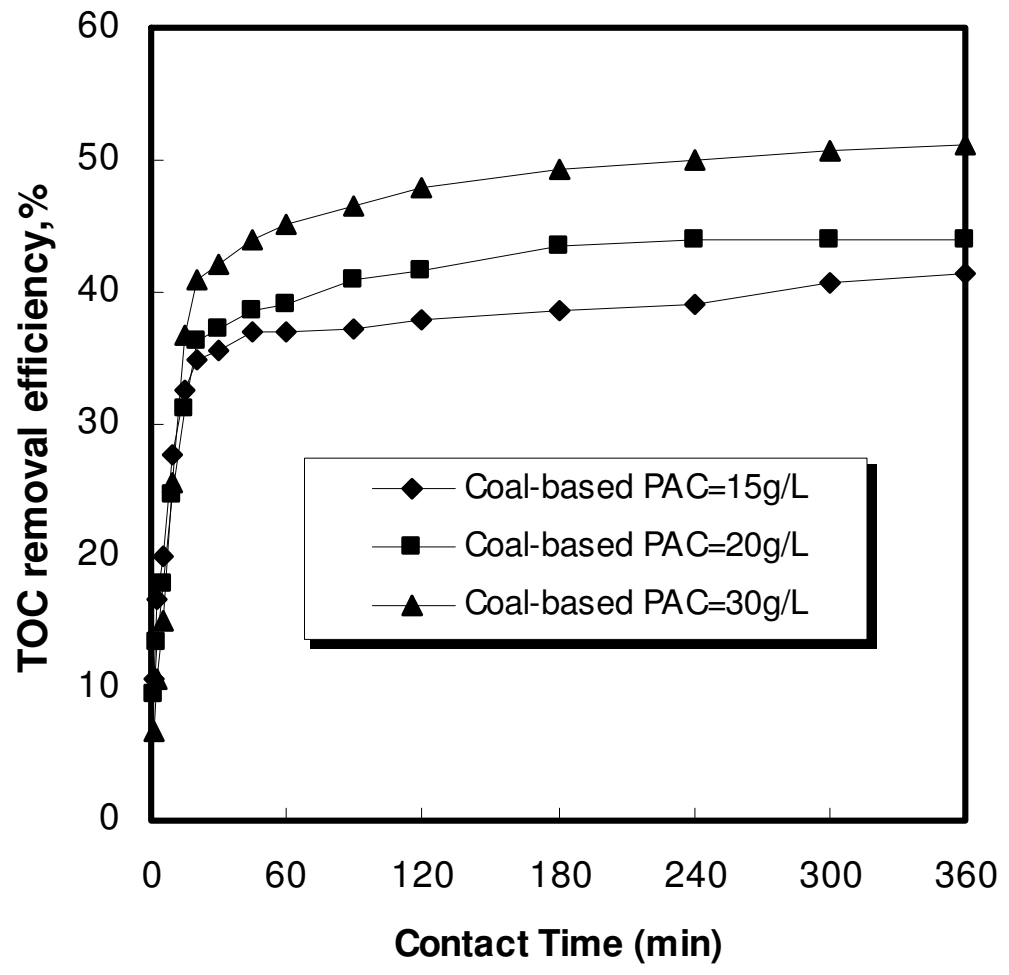


Figure 7 Combination of flocculation-adsorption for TOC removal from landfill leachate (rapid mixing gradient rate $=100 \mathrm{rpm}$, slow mixing gradient rate $=30 \mathrm{rpm}$, average initial $\mathrm{TOC}=110 \mathrm{mg} / \mathrm{L}$ )

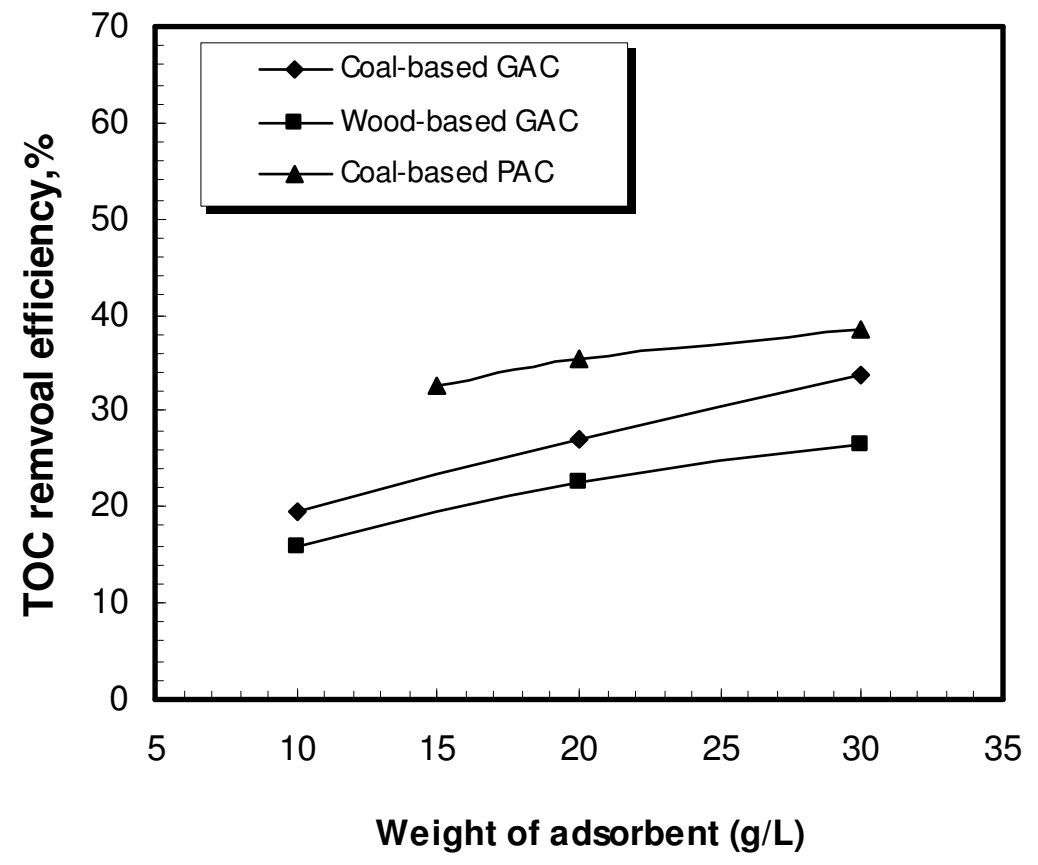


Figure 8 Adsorption equilibrium of synthetic landfill leachate by four kinds of activated carbon with Henry - Freundlich dual model $\left(25^{\circ} \mathrm{C}\right)$

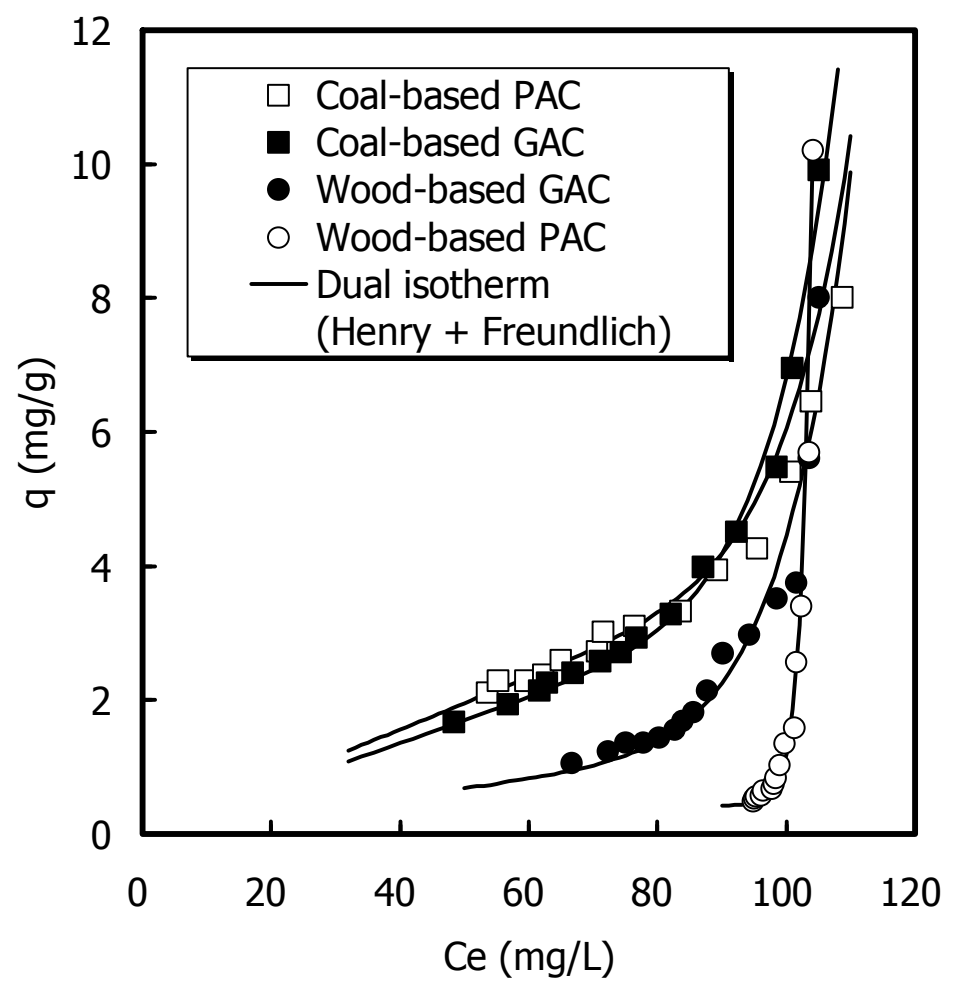


Figure 9 LDFA+Dual isotherm kinetics for TOC adsorption on coal-based GAC

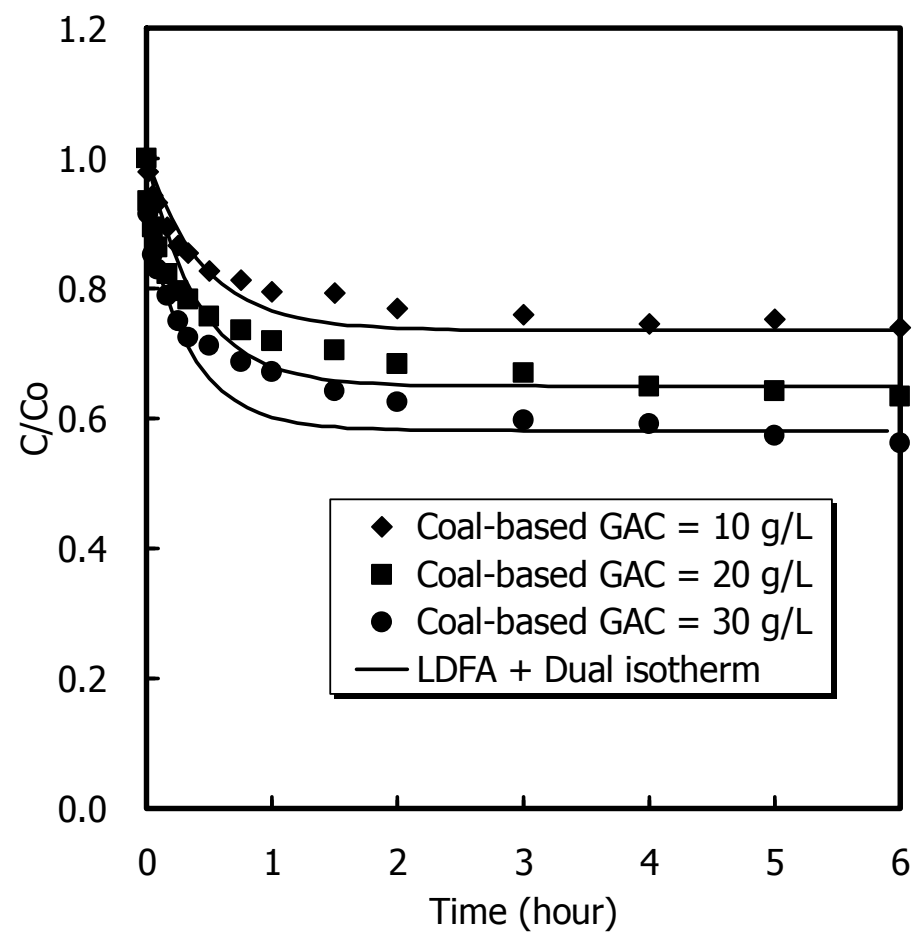


Figure 10 LDFA+Dual isotherm kinetics for TOC adsorption on wood-based GAC

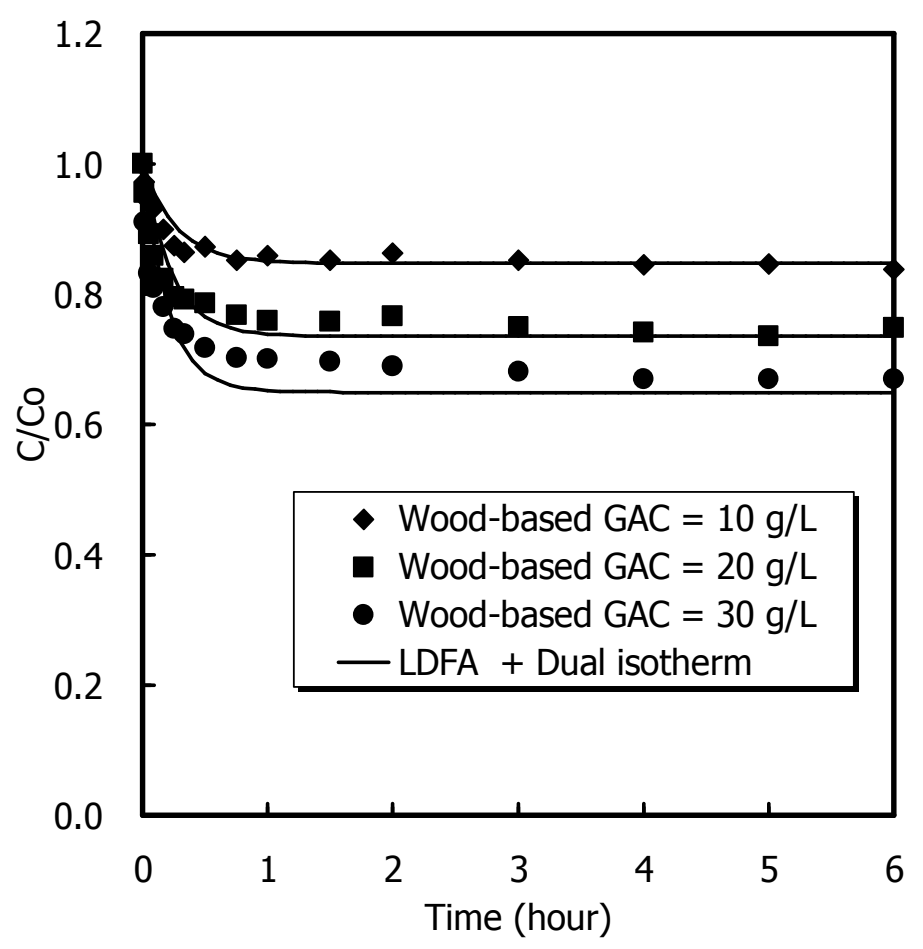


Figure 11 LDFA+Dual isotherm kinetics for TOC adsorption on coal-based PAC

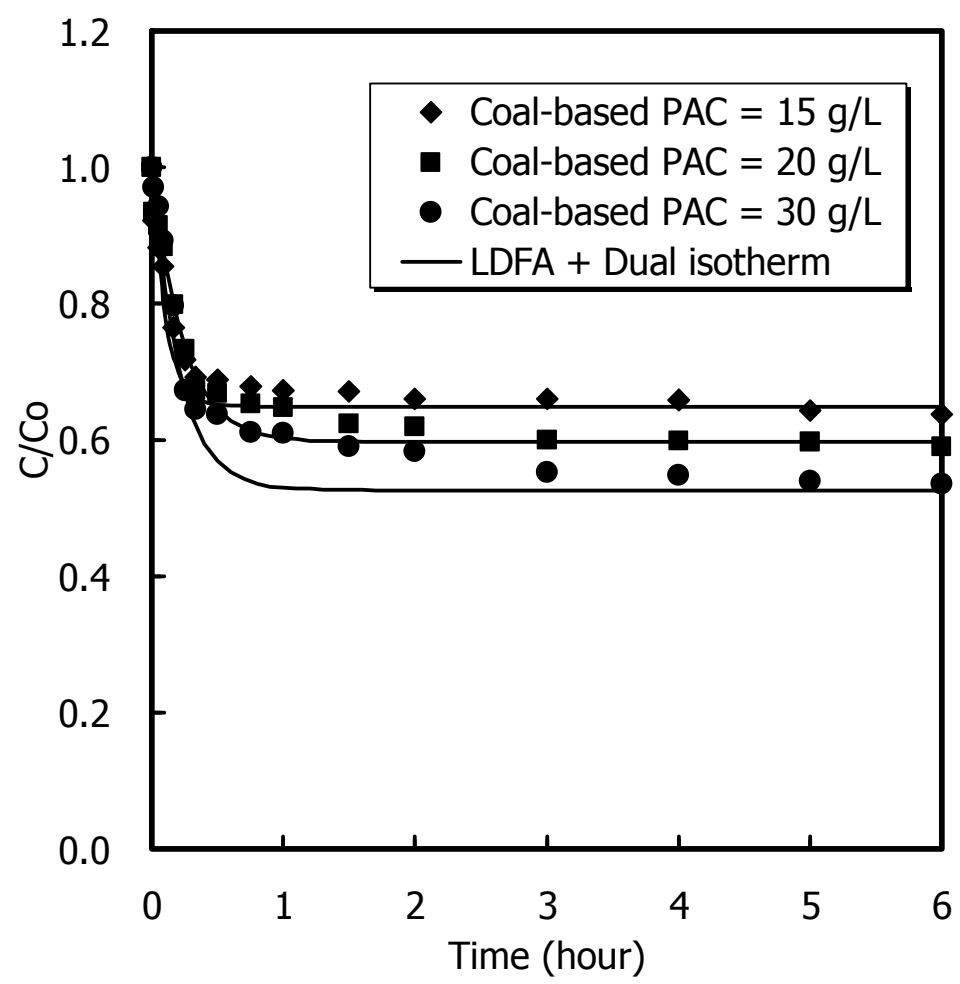


Figure 12 LDFA+ Dual isotherm kinetics for TOC adsorption on wood-based PAC

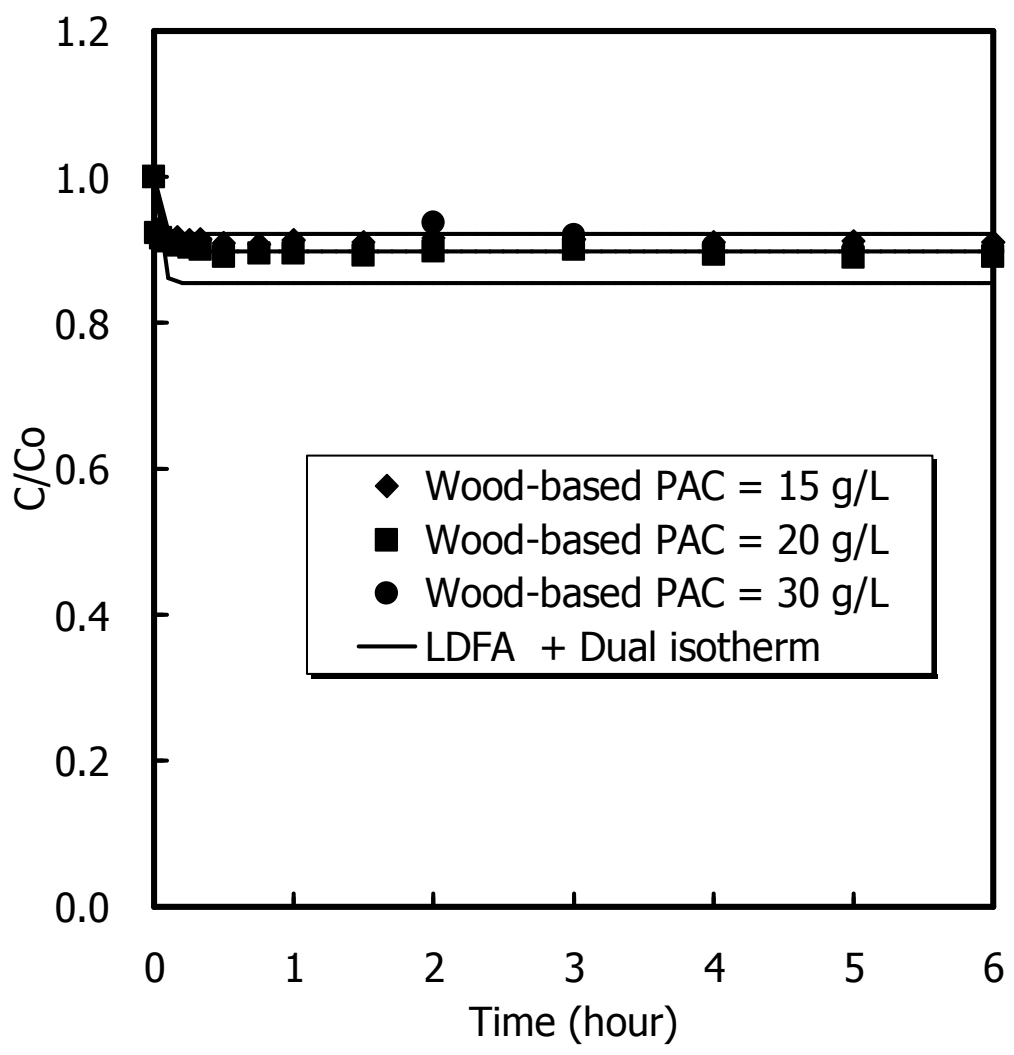

